\title{
Estratégias de marketing na área de sementes
}

\author{
Marketing strategies in the area of seeds \\ Lizandro Ciciliano Tavares ${ }^{1 *}$, André Oliveira de Mendonça', Gizele Ingrid Gadotti²,
Francisco Amaral Villela ${ }^{1}$
}

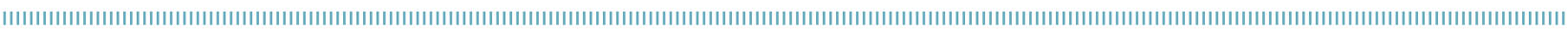

RESUMO: O marketing na área de sementes é um instrumento promissor para o aumento da taxa de utilização de sementes certificadas. Objetivou-se no presente trabalho analisar o marketing como ferramenta para promover o aumento da taxa de utilizaçáo de sementes certificadas. Vale ressaltar que o não pagamento de royalties com a compra de sementes clandestinas descapitaliza a indústria de sementes e reduz o investimento em novas tecnologias e cultivares pelos setores público e privado, diminuindo consequentemente à probabilidade de sucesso dos agricultores pela utilizaçáo de tecnologias ultrapassadas. De maneira geral, verifica-se que o marketing na área de sementes é um importante recurso empregado pelas empresas de sementes, a fim de superar a concorrência e atender às exigências do mercado $e$, por conseguinte, promover $o$ aumento da taxa de uso de sementes certificadas pelos agricultores.

PALAVRAS-CHAVE: certificação de sementes; planejamento estratégico; agricultores; royalties; mercado de sementes.

\begin{abstract}
The marketing in the seeds is a promising tool for increasing the utilization of certified seed. The objective of the present study was to analyze seed marketing as a tool to promote the use of certified seed. It is noteworthy that non-payment of royalties by buying clandestine seeds undercapitalizes seed industry and reduces investment in new technologies and cultivars by public and private sectors, thereby decreasing the likelihood of success of farmers for the use of outdated technology. In general, the use of marketing in the seeds is an important tool used by seed companies in order to outperform the competition and meet market demands and consequently promote increased utilization of certified seeds by farmers.
\end{abstract}

KEYWORDS: seed certification; strategic planning; farmers; royalties; market seed. 


\section{INTRODUÇÃO}

$\mathrm{O}$ acentuado crescimento populacional e o consequente incremento do requerimento mundial por alimentos vêm aumentando de maneira significativa, fazendo-se necessário o aumento da demanda por alimentos, água e energia. A produção agrícola terá de aumentar, por exemplo, de 70 a 100\% até o ano de 2050. Diante disso, há a necessidade de que o melhoramento de plantas e a indústria de sementes do mundo sejam eficientes na condução de seus trabalhos, pois cada vez mais o progresso da produçáo é resultante do progresso genético alcançado pelos melhoristas de plantas e cada vez menos decorrente da melhoria de técnicas agrícolas como adubação e aplicação de agrotóxicos (ABRASEM, 2012).

Seguindo essa tendência, a produção de sementes certificadas cresceu 23\% na safra 2011/12 em relação à safra anterior. Conforme o balanço anual da Associação Brasileira de Sementes e Mudas (Abrasem, 2012), as empresas de sementes produziram mais de 2,99 milhóes de toneladas no período. As sementes certificadas são aquelas produzidas para o mercado, com garantia de procedência e com parâmetros de qualidade (física, sanitária, fisiológica e genética). Há a cobrança de royalties de espécies cujas sementes possuem alguma tecnologia incorporada que possa ser protegida, pela tecnologia nela contida. No Brasil, o mercado de sementes disputa espaço com as chamadas sementes "salvas", guardadas pelos próprios produtores rurais de uma safra para outra, e com sementes clandestinas oriundas de outros países, ou seja, ambas sem pagamento de royalties e sem procedência de qualidade.

Em 25 de abril de 1997 foi aprovada a Lei federal n. ${ }^{\circ} 9.456$ (Lei de Proteção de Cultivares - LPC), cujo regulamento se deu pelo Decreto no 2.366 , de 5 de novembro do mesmo ano. Portanto, há mais de dez anos, quem registra um novo cultivar no Brasil tem seus direitos reconhecidos por meio da referida legislação, um marco que representa a mudança no ambiente institucional que pauta as relaçóes comerciais nesse mercado.

No âmbito desse novo aparato institucional, foi criado o Serviço Nacional de Proteção de Cultivares (SNPC), que mantém o cadastro nacional de cultivares protegidos. Nele estão contidos o nome e o endereço do titular da proteção, além de o órgão ser competente para o exercício da "proteção de cultivares" no Brasil (Marquesan et al., 2010). Marquesan et al. (2010) salientaram que o principal objetivo da legislação é resguardar o conhecimento científico, além de oferecer meios efetivos no sentido de preservar a competitividade das organizaçôes dedicadas a atividades de pesquisa e desenvolvimento em sementes. Isso permite a pessoas físicas e instituiçôes que realizam o melhoramento de plantas a cobrança de royalties ou similar sobre a tecnologia protegida em novas cultivares que são disponibilizadas ao mercado. Em um trabalho realizado no estado do Paraná com o objetivo de analisar o processo de transferência de tecnologia em cultivares de trigo, verificou-se que a produção de trigo aumentou significativamente da safra 1997/98 em diante, quando a LPC passou a vigorar (TAvares et al., 2011).

A visão moderna do agronegócio baseia-se numa perspectiva ampliada que engloba os atores iniciais, os clientes e os consumidores de um produto e/ou serviço agroindustrial até os atores finais, os fornecedores de insumos para os agricultores. Essa visão nas últimas duas décadas forçou as empresas, além de focar em eficiência e na redução de custos, a buscarem mais proximidade com seus clientes (CANEVER et al., 2011). Inseridas nesse ambiente de mudanças, risco e incerteza crescente, as empresas do agronegócio em geral e, especialmente, as produtoras de sementes também são instigadas a buscar estratégias competitivas e a repensar suas formas de organização, tanto em nível interno de concepção e execução da produção como em nível externo, em suas relaçóes com outras empresas. Assim, o fortalecimento de relacionamento com atores externos é fonte importante de valor gerado e percebido pelo mercado (CANEver et al., 2012).

$\mathrm{O}$ marketing rural compreende todas as açóes desenvolvidas para a venda de produtos e serviços agropecuários e para a fixação de uma imagem positiva das empresas que atuam no setor (AgRICOMA, 2014). Ele apenas recentemente recebeu mais importância, por conta sobretudo da elevada participação do agronegócio no produto interno bruto (PIB) dos países, particularmente no Brasil. As grandes empresas realizam com relativo sucesso o marketing rural, promovendo açôes e atividades com diferentes públicos, no entanto as empresas agroindustriais que não se profissionalizaram, principalmente as pequenas, têm falhado no seu esforço de comunicação, tendo em vista que elas permanecem apegadas a uma visão tradicional, pouco interessadas em compartilhar informaçóes com a sociedade (Мотт, 2009).

$\mathrm{O}$ marketing no mercado de sementes utiliza os mesmos conceitos aplicados em outros setores do agronegócio em que tem sido largamente trabalhado o composto mercadológico (produto, preço, distribuição e promoção), entretanto, poucos estudos têm sido realizados considerando as peculiaridades das empresas de sementes (Acosta et al., 2002).

$\mathrm{O}$ marketing preconiza há muito que, para ser efetivo no mundo dos negócios, é condição sine qua non ser mais efetivo do que os competidores nas atividades e nos processos que visam determinar as necessidades dos mercados-alvo e satisfazer a elas (CANEver et al., 2011). Nesse contexto, objetivou-se elaborar e discutir estratégias de marketing para empresas de sementes, ressaltando a importância dessa ferramenta na promoção do aumento da taxa de utilização de sementes certificadas.

Nessa perspectiva, formula-se a questão central desta pesquisa: o marketing na área de sementes é capaz de promover o aumento da taxa de utilizaçáo de sementes certificadas?

O Brasil tornou-se em pouco tempo um dos líderes globais do setor agrícola, e em 2012 o agronegócio representou 23\% do PIB nacional, contribuindo fortemente na geração 
de empregos e divisas para o país. O mercado mundial de sementes é um dos mais importantes para o setor agrícola, movimentando mais de US $\$ 42$ bilhóes por ano, sendo o Brasil responsável por US\$ 2,6 bilhóes (AвRASEm, 2012). O comércio internacional de sementes movimenta cerca de U\$\$ 8,3 bilhóes. O Brasil possui uma sólida e robusta indústria de sementes e um dos maiores parques produtivos do mundo, contando com 1.218 unidades armazenadoras, 673 unidades operacionais de beneficiamento, mais de 5 mil técnicos envolvidos diretamente na produção de sementes, com 168 laboratórios de sementes, dos quais 10 são específicos para análise de organismos geneticamente modificados, e mais de um milhão de empregos gerados (ABRASEm, 2012).

Os agricultores usaram 1,66 milhão de tonelada de sementes certificadas na safra 2011/12, um aumento de $22 \%$ sobre a safra anterior. Os números ainda estáo distantes do pleno potencial do mercado brasileiro, estimado pela Abrasem em 2,55 milhóes de toneladas na última temporada. Mesmo assim, sua participação vem crescendo ano após ano e, na última safra, avançou três pontos percentuais, alcançando $65,1 \%$ de todas as sementes cultivadas no país. Foi a maior taxa de utilização de sementes já registrada no Brasil. Vale ressaltar que as culturas de milho, soja e algodáo juntas representaram mais de 77\% do mercado brasileiro de sementes (ABRASEM, 2012).

\section{Marketing no agronegócio}

O agronegócio ocupa posição de destaque por diversas razóes, tais como: segurança alimentar, qualidade de vida, geração de renda, entre outros. Os desafios para esse setor são: produzir mais, degradando menos e a custos competitivos; gerar capacidade de diferenciaçấo de produtos e de mercados; abrir novas oportunidades para produtores; enfrentar os novos requisitos competitivos dos mercados interno e externo; e estar atualizado para atender aos novos padróes de consumo. Esses fatores requerem a implementação de uma política tecnológica voltada para as atividades ligadas ao agronegócio (Almeida, 2011).

Recentemente, a agricultura passou a ser vista como um amplo e complexo sistema que inclui não apenas as atividades na propriedade rural (na "porteira agrícola") como também, e sobretudo, as atividades de distribuição de suprimentos agrícolas (insumos), de armazenamento, de processamento e de distribuição dos produtos agrícolas. Os sistemas que constituem o agronegócio são, em essência, uma rede de mercados interligados. A identificação da natureza e finalidade desses mercados, seu aperfeiçoamento e otimizaçáo e o ajuste de seus comportamentos aos objetivos socioeconômicos da nação são tarefas do marketing. O marketing do agronegócio assume destacado papel no processo evolutivo da agropecuária, que, ao mesmo tempo em que se torna mais complexo e diferenciado em seus mecanismos internos, mais se integra no processo econômico como um todo, descaracterizando-se como uma fase distinta da economia (GestÃo nO CAMPO, 2014).

\section{Marketing em sementes}

$\mathrm{O}$ conceito de marketing preconiza que as empresas devem criar compostos de marketing, que são os quatro elementos básicos que compóem qualquer estratégia de marketing preço, praça, produto, promoção —, que satisfaçam (gerem utilidades) os clientes. Por trás do ato quase sempre visível de se fazer uma compra, existe um processo de decisão que precisa ser investigado (CANever et al., 2012). No mundo moderno fazer marketing não é mais apenas aprender a se relacionar com a distribuição e com os clientes reais e potenciais. O marketing vive cada vez mais no gene das organizaçóes e ele precisa envolver e estar comprometido com os consumidores, com os fornecedores de tecnologia, com as entidades representativas dos consumidores, com a mídia e com a política evolutiva da saúde humana acima de todas as coisas (TEJON, 2011).

$\mathrm{O}$ marketing de sementes pode ser considerado o desempenho de atividades que direcionam o fluxo de produtos e serviços da indústria de sementes para os agricultores. Dessa forma, o marketing de sementes deve enfocar principalmente o agricultor, porém, procurando atender, além de suas expectativas e necessidades, às demandas dos segmentos das cadeias agroalimentares que vão comprar sua produçáo. Também devem ser observadas as demandas dos consumidores finais das cadeias dos produtos (espécies) envolvidos na comercializaçáo de sementes, já que essas demandas influenciam diretamente as decisões do agricultor no momento da escolha dos cultivares que serão semeados na próxima safra (Abrasem, 2001).

As açôes de marketing devem preocupar-se para que as sementes comercializadas pela empresa cheguem aos agricultores, em tempo e no lugar certo (antes da época recomendada de semeadura em cada regiáo). Náo simplesmente uma semente, mas com ela uma série de outros componentes, incluindo um exaustivo trabalho de pesquisa, tanto pelo melhoramento vegetal como pela indústria de sementes que está inserida nas sementes. A produção e garantia de qualidade, a embalagem, a promoção, a marca e a assistência técnica e toda a tecnologia necessária para que o agricultor consiga obter o máximo desempenho agronômico (potencial genético de determinada cultivar possa oferecer) devem prevalecer pelas estratégias de marketing. Tudo isso com o intuito de promover retornos náo só ao produtor e/ou vendedor, no entanto, sobretudo lucros ao comprador das sementes (AlmeIda, 2011).

Por causa do relacionamento estreito entre a área de marketing e o consumidor, o pessoal destinado aos programas de marketing deve ter conhecimento de relaçóes humanas, comunicaçôes, técnicas de marketing, logística e gerenciamento de negócios. Assim, o pessoal que for atuar na área precisa ser treinado e ter conhecimentos específicos. Para as empresas que atuam no mercado de sementes, o marketing passa a ser ferramental importante para o desempenho de atividades que direcionam seus produtos e serviços para as demandas dos agricultores para os quais sua produção está direcionada, 
gerando lucros e atingindo os objetivos da empresa, decorrente da satisfação dos consumidores de seus produtos e serviços.

As funçôes do marketing de sementes são: determinaçáo das necessidades do consumidor, que inclui a demanda de mercado, a pesquisa de mercado e a previsão de vendas; disponibilidade das sementes (estocagem), referindo-se à produção própria e à revenda; comunicação com o mercado consumidor de sementes, englobando a promoção e as relaçóes públicas, as vendas e o desenvolvimento de distribuidores; distribuição, compreendendo os canais de distribuição e a logística (embalagem, armazenamento, estocagem, transporte, cobertura de riscos); determinação de preços, que abrange os custos fixos e os variáveis, o lucro e os fatores de mercado (ABEAs, 2007).

Os agricultores buscam constantemente por melhores eficiências, com economia e ganhos de produtividade. BATALHA; Silva (1995) sugeriram que, pela grande exigência por parte dos agricultores, o aumento do consumo de produtos alimentares, com menor aplicação de agrotóxicos, torna-se uma interessante estratégia, ou seja, investir em tecnologias de produção, armazenamento e transporte. Entre essas tecnologias, destaca-se como uma das principais o uso de sementes e cultivares desenvolvidas e produzidas obedecendo às normas oficiais, que garantem alto potencial produtivo, sanidade de plantas e, em alguns casos, características diferenciadas para mercados específicos de consumo (maior teor de nutrientes nas sementes e/ou grãos em uma região específica).

As funçôes do marketing de sementes, segundo Almeida (2006), é a determinação das necessidades do consumidor, isto é, verificar a disponibilidade de sementes, desenvolver comunicação com o consumidor por intermédio de relaçôes públicas, controlar a distribuição dos produtos e trabalhar com a determinação de preços. Ainda conforme o autor, vê-se que no mercado de grãos a competitividade é uma variável crítica, pois os fatores mais importantes para os agricultores sấo produtividade e tecnologia, áreas nas quais empresas buscam novos conhecimentos mediante estudos e pesquisas. Diante disso, cabe às empresas elaborar planos de marketing com estratégias que proporcionem o acompanhamento da evoluçáo do mercado, dos produtos e dos segmentos atuais e potenciais, baseando-se na necessidade e no desejo dos produtores e ajudando-os a tomar decisões com relação à produção e comercializaçáo de sementes.

A comunicação com o mercado envolve todas as maneiras de transmitir informaçóes aos agricultores e/ou produtores sobre as sementes que são produzidas e comercializadas pela empresa. Agricultores e produtores devem ser informados de forma persuasiva, de maneira que eles sejam influenciados a efetuar a compra de determinadas sementes em dada empresa. É por meio da comunicação mercadológica que o agricultor será influenciado, pela promoção, abrangendo venda pessoal, relaçôes públicas, propaganda e promoção de vendas. Os agricultores consideram ao adquirir sementes: menor custo e mais benefícios, confiança na semente, praticidade no uso da semente, compatibilidade da semente com as necessidades, visibilidade e rapidez com que as vantagens do produto são percebidas pelo produtor (RigatTo, 1999).

\section{Composto de marketing}

O composto de marketing na área de sementes, assim como em outras áreas, pode ser classificado em quatro categorias: produto, preço, praça (cadeia produtiva/distribuiçãa) e promoção. Essas variáveis são conhecidas como marketing mix ou os 4 Ps de marketing, que se originaram dos termos em inglês product, price, place e promotion. Elas devem ser controladas pelo gestor de marketing, a fim de satisfazer ao seu cliente-alvo, e as empresas têm de gerar uma resposta positiva ao seu mercado-alvo mediante a combinação desses quatro elementos. Ou ainda, o marketing mix é o conjunto de ferramentas que a empresa utiliza para perseguir seus objetivos de marketing (criar valor) no mercado-alvo e alcançar os objetivos. A seguir, seráo apresentados os quatro elementos do composto (mix) de marketing (CANEVER et al., 2012).

A estrutura do mix de marketing é composta segundo Canever et al. (2012) por: produto, preço, praça ou cadeia produtiva, e promoção. O composto marketing é ilustrado na Figura 1.

Produto sucintamente se refere à combinaçáo de bens e serviços que a empresa disponibiliza aos agricultores. O produto constitui um conjunto de atributos, funçôes e benefícios e pode ser composto de características físicas "tangíveis", as quais estão relacionadas diretamente com sua qualidade (por exemplo, o tamanho, a uniformidade, a germinaçáo e o vigor da semente). Porém, do produto também fazem parte os serviços oferecidos e a marca, que são atributos "intangíveis" e que caracterizam a sua qualidade extrínseca. As decisóes de produto incluem aspectos como função, aparência, embalagens, serviços, garantias, etc. O produto deve ser desejado pelo cliente e beneficiá-lo por: benefício núcleo (razão da compra da semente), produto básico (no caso da semente, aquilo que toda semente deve apresentar, como alta sanidade, vigor, germinação, pureza, entre outros), produto real ou esperado

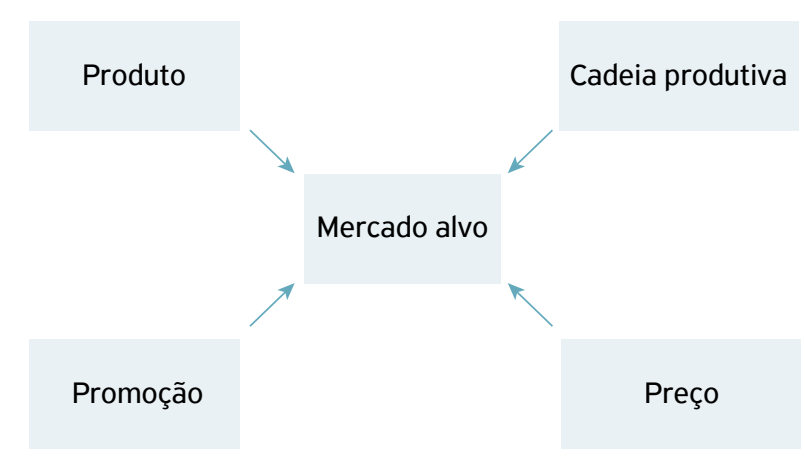

Fonte: CANEVER et al., 2012.

Figura 1. O composto de marketing. 
(expectativas do cliente quanto à qualidade, marca, embalagem, confiabilidade, segurança etc.), produto ampliado (serviços e benefícios adicionais que não são esperados pelos clientes, mas que podem ser adicionais) e produto potencial (ampliaçóes e inovaçôes que podem ser adicionadas ou introduzidas ao produto no futuro) (CANEver et al., 2012).

Por sua vez, preço é parte do custo total que os clientes pagam numa troca. Trata-se do único componente do composto de marketing que gera receita, enquanto os outros 3 Ps são custo da empresa. Há custo para produzir, para organizar a cadeia produtiva e para promover os produtos/serviços, e os preços devem suportar esses elementos do mix de marketing. A determinaçáo do preço do produto não é algo simples e tem de necessariamente refletir as relaçôes entre a oferta e a demanda. Assim, na determinação da estratégia de preço da semente, alguns aspectos precisam ser observados: primeiramente, o preço deve ser capaz de gerar lucro à empresa, portanto, necessita ser maior que o custo de desenvolvimento e produção, porém, não alto a ponto de desestimular a compra. Em segundo lugar, deve ser suficientemente baixo a ponto de ser atrativo aos clientes, mas náo táo baixo de modo a depreciar o produto aos olhos dos clientes (CANEver et al., 2012). Além disso, na definição do preço da semente, devem-se considerar a estrutura de custos da empresa, a concorrência atual e potencial naquele mercado, os objetivos da empresa, os segmentos de mercado, bem como o posicionamento (por exemplo, preço-qualidade) que se pretende dar à semente no tocante às alternativas do mercado. Em conformidade com Kotler; Armstrong (2003, p. 48), corresponde à "quantia de dinheiro que os clientes têm de pagar para obter um produto".

Já praça ou cadeia produtiva consiste numa rede ou num sistema organizado de instituiçóes que executam todas as funçóes necessárias, a fim de realizar a tarefa de marketing de ligar os produtos e serviços aos usuários. O objetivo da cadeia produtiva é disponibilizar o produto/serviço ao cliente final de forma fácil e conveniente para ser adquirido, porém nenhuma empresa do setor sementeiro pode executar todas as atividades e tarefas sozinhas. Ela precisa, à montante, contar com os fornecedores de insumos (material genético, máquinas, fertilizantes, multiplicadores etc.), e à jusante, de distribuidores (atacadistas, distribuidores, representantes, entre outros). Cada empresa de sementes deve "desenhar" sua cadeia produtiva eficientemente, de modo a minimizar os seus custos de transaçáo. As transaçóes podem ser governadas via o processo simples de compra e venda (transaçôes via mercado), integração vertical (a empresa internaliza a transação) e maneira híbrida entre ambas (contratual). A estrutura de governança via mercado possibilita um controle menor sobre o comportamento dos indivíduos, e o sistema básico de ajuste é via preço. A contratual baseia-se em incentivos e/ou restriçóes por meio de contratos formais e informais que permitem controlar ou minimizar a questáo da racionalidade limitada dos agentes e o comportamento oportunista dos possíveis supridores e/ou clientes, além de minimizar problemas de assimetria de informaçōes entre os agentes e/ou organizações econômicas. Já a integração vertical ocorre se os custos de transacionar com agentes externos inviabilizam a atividade (CANever et al., 2012). Para Kotler (2009), praça é o modo pelo qual a empresa torna seus bens acessíveis e disponíveis ao público-alvo.

A promoção, por fim, representa os vários aspectos da comunicaçáo do seu produto ou serviço com o objetivo de gerar respostas positivas dos clientes. Portanto, além de desenvolver uma ótima semente a um preço atraente e torná-la acessível, há a necessidade de comunicar-se com os atuais e potenciais interessados. Quando se pretende comunicar com o público, sugerem-se algumas alternativas: propaganda, que é a comunicação paga e não pessoal feita pela mídia de massa; relaçôes públicas, a qual objetiva desenvolver uma imagem positiva ou proteger a imagem da organização, normalmente não é paga e ocorre via uma variedade de programas e açóes para construir relacionamentos com a sociedade de modo a obter publicidade favorável; promoção de vendas, comumente usada para obter aumentos nas vendas no curto prazo e possível de ser sintetizada em redução de preços e ofertas especiais para encorajar a experimentação da semente ou a sua compra; vendas pessoais, isto é, a interaçáo pessoal com o cliente visando apresentar a semente, responder a perguntas e tirar pedidos de sementes; e marketing direto, ou seja, a utilização de correio, telefone, $e$-mail ou internet para o envio de material publicitário, para comunicar-se diretamente com clientes identificados atuais e potenciais. Atualmente, o marketing direto está em alta pelas facilidades propiciadas pela internet no envio de material de comunicação personalizado a cada cliente (Canever et al., 2012).

Constata-se que o mix de marketing é composto de variáveis internas que são controláveis pela empresa, estando estas sujeitas a sofrer influência de variáveis externas que não podem ser controladas pela empresa, como legislação, cultura, economia, sistema social, entre outros. Existe a necessidade constante de que o composto de marketing seja revisado e modificado diante de alteraçóes e condiçóes de mercado, com o intuito de levar ao consumidor visado ao produto certo (pretendido), no lugar e no momento certo (oportuno) e ao preço certo (adequado) (GIL, 2008).

\section{ANÁLISE}

Nos países em desenvolvimento, as variedades melhoradas das principais culturas alimentares começaram a ser lançadas em centros internacionais de pesquisa agrícola, em 1960, proporcionando assim a base para a revolução verde em arroz e trigo. Esta, por sua vez, estimulou projetos para estabelecer mecanismos de fornecimento de sementes organizados em muitos 
países ao longo dos anos 1970, esforço que continuou nas duas décadas seguintes.

Todavia, veio uma desilusão gradual com muitas dessas iniciativas, por causa de sua penetração relativamente baixa no "mercado", de maneira especial para os pequenos agricultores. Havia muitas causas para esse subdesempenho, incluindo variedades inadequadas, má distribuição e sistemas de marketing, qualidade variável de sementes e infraestrutura fraca. Além disso, as expectativas dos projetos iniciais eram muitas vezes bastante irrealistas. Tais projetos perseguiram ambiciosas metas de produção, mas deram pouca atenção ao marketing, resultando muitas vezes na venda das sementes a preços subsidiados, ou até mesmo desviados para o mercado de gráos, por falta de demanda. Esses problemas foram muitas vezes explicados como "falta de compreensão" por parte dos agricultores, e a resposta foi montar pesquisas de marketing ou campanhas de extensão. No entanto, os agricultores estáo em geral bastante alertas para a economia de seu ambiente imediato (BISHAw; Turner, 2008).

No Brasil foi confirmado que no estado do Paraná, até o fim da década de 1980, toda a semente básica era distribuída pela Secretaria de Estado da Agricultura, sem a existência de açóes de "marketing" por parte das empresas de melhoramento. A partir daí, essa incumbência passou a ser desenvolvida diretamente pelas empresas de melhoramento. Até o término dos anos 1970, as informaçōes sobre cultivares de soja faziam parte de pacotes tecnológicos elaborados por pesquisadores e agentes da assistência técnica. Esses pacotes tornavam-se normas nas instituiçôes de crédito rural para as operaçôes de financiamento das lavouras de soja. Nesse período, praticamente nenhuma atividade específica de transferência de cultivares foi desenvolvida pela pesquisa, pela assistência técnica ou por empresas de sementes. Essa situação manteve-se até meados da década de 1980, quando foram iniciadas açóes específicas (palestras, dias de campo, publicaçóes, entre outras) para a transferência de informações sobre as cultivares em fase de recomendação para o Paraná, entretanto, tais atividades aconteceram ainda de forma pontual, sem fazer parte de um projeto sistêmico que envolvesse todos os componentes da cadeia produtiva de sementes de soja (Domit et al., 2007).

Para atuar melhor em um mercado que apresenta muitas vezes nível significativo de incerteza, principalmente em relaçáo à adoçấo de novos cultivares, as empresas de sementes necessitam utilizar as ferramentas de marketing disponíveis. Assim, deve-se dar prioridade às ferramentas de marketing mais importantes, como a segmentação cuidadosa (com critérios) dos mercados, a diferenciação da oferta da empresa e o posicionamento consistente da empresa na mente dos consumidores. Portanto, o entendimento do que, onde, quando e como os clientes compram faz-se imprescindível para a elaboração de boas estratégias de marketing.

$\mathrm{O}$ marketing a ser usado pelas empresas produtoras de sementes, sobretudo no que tange à demonstraçáo dos benefícios da compra de sementes certificadas ou pelos malefícios do emprego de sementes clandestinas para os agricultores (Fig. 2), torna-se ferramenta relevante para o aumento da taxa de utilizaçáo de sementes certificadas.

Numa pesquisa realizada em empresas de sementes de trigo e soja, do Rio Grande do Sul, verificou-se que a maioria dos clientes creditou à qualidade da semente o principal fator determinante de compra, o que permite utilizar isso como apoio ao marketing para divulgar a semente, aumentar a eficiência da força de vendas e estimular revendedores (Acosta et al., 2002). De fato, de acordo com estudos desenvolvidos por Peske et al. (1991), a semente é comprada pela germinação, sendo o significado de "semente de alto vigor" desconhecido por aproximadamente $40 \%$ dos agricultores.

Nessa perspectiva, constata-se um importante ramo para as empresas produtoras de sementes atuarem veementemente com estratégias de marketing, apontando os benefícios da utilização de sementes certificadas como um dos diferenciais competitivos. Um exemplo disso é a estratégia de marketing de sementes de milho híbrido. A venda acontece por número de sementes (60 mil sementes por embalagem, nesse caso), em funçáo do alto vigor que se consegue obter. $\mathrm{O}$ agricultor confia nesse número e não mais faz a aquisição baseada no peso do saco daquele híbrido. Essa mudança não é observada em outras espécies. A venda por unidade ocorre em híbridos de hortaliças, mas a tendência é mais associada ao custo do que à qualidade fisiológica.

Os fatores técnicos podem também afetar o sistema de sementes, principalmente o fator organizacional, mas há fatores técnicos que influenciam de modo profundo todos os sistemas de sementes, o comportamento de polinização da cultura e seu "fator de multiplicaçáo" (Bishaw; Turner, 2008). O comportamento reprodutivo da cultura, por autopolinização ou por polinização cruzada, por conseguinte, tem grandes implicaçôes técnicas sobre a manutenção da variedade e os riscos associados à contaminação de fontes externas mediante a

Setor formal $\longleftrightarrow$ Setor informal

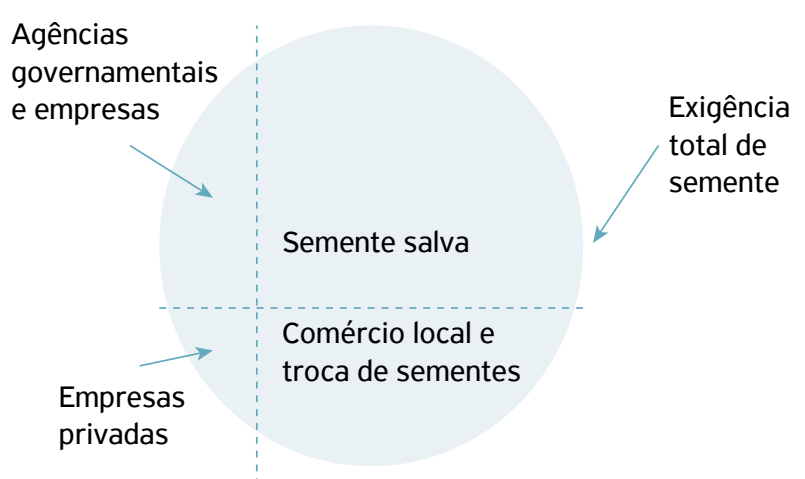

Fonte: BISHAW; TURNER, 2008.

Figura 2. Divisões no sistema de sementes. 
polinizaçáo cruzada. No setor formal de sementes, a multiplicação é controlada por procedimentos sistemáticos incorporados no processo conhecido como "certificaçáo". O setor informal não fornece tais mecanismos de controle (além da boa prática de agricultores individuais) da qualidade da semente, que é, portanto, mais vulnerável à deterioração genética. $\mathrm{O}$ risco de contaminação por mistura mecânica existe em ambos os casos, mas há maior chance de remoçáo durante a produção formal de sementes, por meio de "roguing", por exemplo, na colheita ou pela inspeção em cada etapa do processo de multiplicação (LONDREs, 2014).

Outro importante segmento de atuação do marketing para a indústria de sementes é a prestaçấo de serviços, como a assistência técnica, prestada por técnicos especializados. Cabe salientar que a assistência técnica fornecida pelas empresas de sementes aumenta a probabilidade de sucesso dos agricultores, como, por exemplo, cultivares diferentes para demandas distintas de clima, solo, água e nutrientes. A sanidade das plantas é outro aspecto de atuação dos técnicos, pois as aplicaçôes de agrotóxicos no momento, na dose e nas condiçóes corretas, são importantes para o pleno desempenho genético dos cultivares. A assistência técnica foi o ponto mais relevante que os produtores descreveram que fosse prestado (como serviço) pelas empresas produtoras de sementes, segundo estudo realizado por MarX (2011) na Coopavel Cooperativa Agroindustrial, no estado do Paraná. A maior concorrência e a maior exigência do mercado comprador, segundo TAVAREs et al. (2011), levaram a maior profissionalização e eficiência das empresas produtoras de sementes, e aquelas que náo se adequaram a essa realidade encerraram suas atividades.

GIRARDi (2002) destacou as seguintes estratégias de marketing para cooperativas como forma de potencialização do produto semente de soja, no tocante ao público-alvo:

1. desenvolvimento de intercâmbios com empresas detentoras de material genético e que desenvolvem novos cultivares com maior valor agregado, possibilitando sua colocação no mercado;

2. diferenciação do produto semente por intermédio do serviço de assistência técnica altamente qualificada como forma de potencializar e diferenciar o canal de distribuição e vendas;

3. desenvolvimento de programas de garantia da qualidade, no sentido da busca constante da melhoria da qualidade, consolidando o sistema mediante a certificação ISO 9000;

4. investimento no sentido de maior fixaçáo da marca quanto aos clientes;

5. parcerias com órgãos oficiais como a Empresa Brasileira de Pesquisa Agropecuária (Embrapa), institutos estaduais e outros, com o objetivo de dar maior credibilidade à divulgação dos cultivares de semente comercializada pela empresa;

6. criaçáo de campanhas de vendas, como maneira de motivar a aquisição das sementes;
7. acompanhamento constante do mercado buscando se antecipar às suas mudanças;

8. aprimoramento técnico;

9. fixação da marca;

10. assistência técnica constante e eficaz;

11. agregação de valores ao insumo semente;

12. intensificação de dias de campo em propriedades com alta produtividade;

13. sementes de alta qualidade fisiológica, principalmente em relação à germinação e ao vigor;

14. venda do produto semente acompanhado de tratamento com fungicida;

15. oferta de embalagens práticas e resistentes;

16. destaque dos valores agregados do produto, como qualidade e assistência técnica, em relação ao preço;

17. descontos promocionais para cultivares de menor potencial de mercado;

18. campanhas de venda baseadas no sistema de troca das sementes pelo produto comercial disponível;

19. foco de distribuição e colocação do produto logo após a colheita, caso exista predisposição na aquisiçáo da semente;

20. busca de respaldo da qualidade e eficiência do produto no que concerne aos órgáos oficiais de pesquisa;

21. utilização de boletins e informativos técnicos como maneira de divulgaçáo de resultados e cultivares e como forma de fixação da marca da empresa;

22. utilizaçấo de produtores referenciais como modo de divulgação do produto.

A taxa de utilização de sementes de trigo no Brasil ficou acima de $80 \%$ no período de 1994-2008, mas observou-se diminuição nas últimas safras em virtude do emprego de sementes clandestinas (TaVares et al., 2011). Constata-se que os órgãos competentes devem realizar fiscalizaçôes mais acentuadas e frequentes no comércio de sementes clandestinas e que o marketing na área de sementes pode ser importante ferramenta na demonstração dos benefícios do uso de sementes certificadas para os agricultores. Vale ressaltar que o pagamento de royalties promove a capitalização do setor de sementes e o reinvestimento na pesquisa, oportunizando o lançamento de novas tecnologias e cultivares. Por consequência, isso favorece os agricultores, que vai se beneficiar dessas novas tecnologias (ReIs, 2012).

A ampliação do mercado de sementes com maior número de cultivares, atingindo os diferentes nichos de mercado, apresenta-se como um dos objetivos do marketing de sementes. Para o sucesso nesse setor são relevantes a capacidade de expansão tecnológica, o posicionamento no mercado e a qualidade do produto (VILANI, 2006). As percepções desses fatores evidenciam que as estratégias de marketing são exigências fundamentais para a manutenção das empresas e que a pesquisa de mercado é ferramenta indispensável para demonstrar os benefícios da utilização de sementes certificadas, 
detectando as necessidades e os desejos dos clientes, a fim de superar a concorrência e atender às exigências do mercado. $\mathrm{O}$ impacto de todas as pesquisas de melhoramento de plantas depende da taxa de adoçáo de variedade e/ou da substituição de sementes praticada por agricultores. Há forte ligação entre o melhoramento vegetal formal e o fornecimento de sementes. O surgimento do melhoramento sistemático de plantas gerou novas variedades, impulsionou a multiplicação de sementes e estimulou o marketing por empresas comerciais (Bishaw; Turner, 2008).

No setor de sementes, as inovaçóes tecnológicas são direcionadas para a busca de estratégias competitivas, por intermédio do desenvolvimento de cultivares resistentes a patógenos, estresses abióticos, maior absorção de nutrientes e plantas com arquitetura foliar que possibilitem maior absorçáo da radiação fotossintética, tornando-as consequentemente mais produtivas. Esses cultivares devem ser adaptados às diferentes regiôes edafoclimáticas e estresses abióticos, por exemplo, e novas tecnologias proporcionam diferencial competitivo para empresas, visto que atendem a diferentes segmentos da cadeia produtiva (Rigatto, 1999). A biologia molecular, ao alterar a genética das plantas e sementes, mostra-se uma ferramenta interessante para incorporar novos atributos e especificidades em novos cultivares (Rigatto, 1999). Constata-se que as empresas de semente hoje em dia atuam de forma enérgica em estratégias de marketing voltadas às novas tecnologias, normalmente obtidas pela biologia molecular. Podem ser citados exemplos de tecnologias transgênicas, como soja: Roundup Ready (RR) e Roundup Ready 2 (RR2); milho: RR2 e Herculex; e algodão: RR e Liberty Link.

Ampliar o mercado de sementes, operar com maior número de cultivares e por conseguinte aumentar a taxa de utilização de sementes certificadas, atingindo os nichos de mercado consumidor, apresentam-se como objetivos do planejamento de marketing na área de sementes. As empresas de sementes que pretendem se perpetuar no mercado devem atuar fortemente em estratégias de marketing, visando sempre ao cliente, ou seja, o agricultor.

\section{CONCLUSÃO}

Estratégias de marketing no setor de sementes são capazes de promover o aumento da taxa de utilizaçáo de sementes certificadas.

Em meio a um cenário em que os produtos, os preços e a qualidade são cada vez mais semelhantes e os consumidores cada vez mais informados e exigentes, a simples sobrevivência das organizaçôes traz novos desafios aos profissionais atuantes na gestão das empresas produtoras de sementes, bem como aos responsáveis técnicos do setor. Portanto, compreender os clientes, as suas necessidades e os direcionadores de valor que orientam na escolha de sementes certificadas é fundamental na gestâo estratégica de negócios.

As estratégias de marketing deixaram de ser tendência no mercado e passaram a ser uma realidade para a sobrevivência das empresas no mercado de sementes. As empresas promovem suas marcas por intermédio de produtos diferenciados, como sementes de alta germinação e sanidade, mais produtivas, adaptadas às diferentes condiçóes edafoclimáticas e tolerantes a fatores bióticos e abióticos. Essas são algumas opçôes em que as empresas podem atuar, atingindo diferentes nichos de mercado e ampliando a fatia de mercado, incrementando consequentemente suas receitas.

$\mathrm{O}$ marketing na área de sementes é uma importante ferramenta utilizada pelas empresas, a fim de superar a concorrência, atender às exigências do mercado e, por conseguinte, promover o aumento da taxa de utilizaçáo de sementes certificadas pelos agricultores. Por meio de estratégias de marketing, as empresas podem demonstrar aos agricultores os benefícios do uso de sementes certificadas, bem como os malefícios de sementes "clandestinas e/ou salvas".

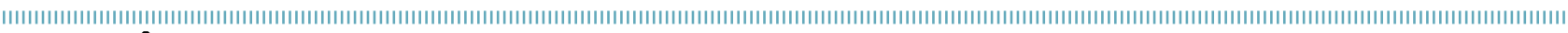
REFERÊNCIAS

ACOSTA, A.; BARROS, A.C.S.A.; PESKE, S.T. Tipologias e composto mercadológico de empresas de sementes de trigo e soja do Rio Grande do Sul. Revista Brasileira de Sementes, v.24, n. 1, p.81-90, 2002. DOI: 10.1590/SO101-31222002000100012

ALMEIDA, F.J. Comercialização de sementes. Curso de especialização por tutoria a distância - ABEAS/Universidade Federal de Pelotas (UFPel). Módulo 10. Brasília, 2011.

ALMEIDA, LE.S.R. A distintividade como uma função dinâmica da marca: o registro marcário, a degenerescência e o significado secundário. In: SEMINÁRIO NACIONAL DA PROPRIEDADE INTELECTUAL, 26., 2006, Genebra, Suíça. Anais. Genebra, Suíça: 2006. Painel Ix.
ASSOCIAÇÃO BRASILEIRA DE EDUCAÇÃO AGRÍCOLA SUPERIOR - ABEAS. Comercialização de sementes. Tutor: Fernando José de Almeida. Brasília: ABEAS; Pelotas: Universidade Federal de Pelotas/Departamento de Fitotecnia, 2007. 88p. (Curso de Ciência e Tecnologia de Sementes. Módulo 10.)

ASSOCIAÇÃO BRASILEIRA DE SEMENTES E MUDAS. Anuário ABRASEM. Brasília: ABRASEM, 2001.

ASSOCIAÇÃO BRASILEIRA DE SEMENTES E MUDAS ABRASEM. Anuário ABRASEM, 2012. Pelotas: Becker e Peske, 2012. 
BATALHA, M.O.; SILVA, A.L. Marketing \& agribusiness: um enfoque estratégico. Revista de Administração de Empresas, São Paulo, v.35, n.5, p.30, 1995.

BISHAW, Z.; TURNER, M. Linking participatory plant breeding to the seed supply system. Euphytica, n. 163, p.31-44, 2008. DOI: 10.1007/s10681-007-9572-6

CANEVER, M.D.; KOHLS, V.K.; PESKE, S.T. A indústria de sementes de hortaliças e o marketing estratégico. In: NASCIMENTO, M.W. (Ed.). Hortaliças: tecnologias de produção de sementes. Brasília: Embrapa Hortaliças, 2011. p.11-33.

CANEVER, M.D.; KOHLS, V.K.; STASINSKI, R. Da gestão da produção ao marketing: uma agenda estratégica para o agronegócio sementes. In: PESKE, S.T.; VILLELA, F.A.; MENEGHELLO, G.E. Sementes: fundamentos científicos e tecnológicos. 3.ed. Pelotas: Ed. Universitária/UFPel, 2012. 573p.

COMUNICAÇÃO EM AGRIBUSINESS \& MEIO AMBIENTE AGRICOMA. Marketing rural. Disponível em: <http://www. agricoma.com.br/agricoma/conceitos/mkt_rural.php >. Acesso em: 3 fev. 2014

DOMIT, L.A.; PIPOLO, A.E.; MIRANDA, L.C.; GUIMARAES, M.F. Transferência de tecnologia para cultivares de soja desenvolvidas pela Embrapa Soja para o Paraná. Revista Brasileira Sementes, v.29, n.2, p.1-9, 2007.

GESTÃO NO CAMPO. Conceito de agronegócio. Disponível em: <http://www.gestaonocampo.com.br/conceito-de-agronegocio/>. Acesso em: 7 maio 2014.

GIL, C. Variáveis de decisão de marketing em serviços de demanda não desejada: dois casos no setor de seguros. 2008. 157p. Dissertação (Mestrado em Administração) - Universidade de São Paulo, São Paulo, 2008.

GIRARDI, R.E. Estratégias de marketing no agronegócio de semente de soja. 2002. 125p. Dissertação (Mestrado em Engenharia de Produção) - Universidade Federal de Santa Catarina, Florianópolis, 2002. 125p.

KOTLER, P. Marketing para o século XXI: como criar, conquistar e dominar mercados. São Paulo: Ediouro, 2009.
KOTLER, P.; ARMSTRONG, G. Princípios de marketing. $9^{\text {th }}$ ed. São Paulo: Prentice Hall, 2003.

LONDRES, F. A associação biodinâmica e o desafio da produção de sementes de hortaliças. Rio de Janeiro: AS-PTA, 2014. $51 \mathrm{p}$.

MARQUESAN, F.F.S.; KOHLS, V.K.; RIGATTO, P. Pesquisa e desenvolvimento no setor de sementes de arroz irrigado no Rio Grande do Sul. Revista Eletrônica de Administração, v.16, n.3, p.470-490, 2010.

MARX, A.C. Estratégia de marketing das sementes Coopavel. 2011 . 50f. Dissertação (Mestrado em Ciência e Tecnologia de Sementes) - Programa de Pós-Graduação em Ciência e Tecnologia de Sementes, Universidade Federal de Pelotas, Pelotas, 2011.

MOTT, D. Marketing rural. 2009. Disponível em: <http:// mkt-negocios.blogspot.com/2009/08/marketing-rural.html>. Acesso em: 23 jan. 2014.

PESKE, S.T.; BAUDET, L.; BARROS, A.C.; IRIGON, D.L. Perfil do agricultor em relação ao uso de sementes. Informativo ABRATES, Brasília, v.1, n.4, p.47, 1991

REIS, M.R. Tecnologia social de produção de sementes $e$ agrobiodiversidade. 2012. 288f. Dissertação (Mestrado em Desenvolvimento Sustentável) - Universidade de Brasília, Brasília, 2012.

RIGATTO, P. Comercialização de sementes. Curso de especialização por tutoria a distância - ABEAS/Universidade Federal de Pelotas (UFPel). Módulo 10. Brasília, 1999.

TAVARES, L.C.V.; BASSOI, M.C.; MIRANDA, L.C.; PRETE, C.E.C. Transferência de tecnologia para cultivares de trigo no estado do Paraná. Revista Brasileira de Sementes, v.33, n. 1, p.21-27, 2011.

TEJON, J.L.M. Agronegócio sem marketing é só agro, sem negócio. Feed \& Food, ano 5, n.55, p.32-33, 2011.

VILANI, J.B. Fatores que o agricultor leva em consideração para escolher a semente de soja. 2006. 54f. Dissertação (Mestrado em Ciência e Tecnologia de Sementes) - Programa de Pós-Graduação em Ciência e Tecnologia de Sementes, Universidade Federal de Pelotas, Pelotas, 2006. 